\title{
TWO-COMMODITY PERISHABLE INVENTORY SYSTEM WITH BULK DEMAND FOR ONE COMMODITY
}

\author{
V.S.S. Yadavalli ${ }^{1}$, O. Adetunji ${ }^{2}$, B. Sivakumar ${ }^{3}$ and G. Arivarignan ${ }^{4}$ \\ ${ }^{1,2}$ Department of Industrial \& Systems Engineering \\ University of Pretoria, South Africa \\ sarma.yadavalli@up.ac.za, olufemi.adetunji@up.ac.za \\ ${ }^{3,4}$ Department of Applied Mathematics and Statistics, \\ Madurai Kamaraj University, India \\ sivabkumar@yahoo.com, arivarignan@yahoo.com
}

\begin{abstract}
This article considers a two-commodity continuous review inventory system in which the arriving customers belong to any one of three types, such that type 1 customers demand a single item of the first commodity, type 2 customers demand bulk items of the second commodity, and type 3 customers demand one item of the first commodity and bulk items of the second commodity. The arrivals of all three types of customers are assumed to be a Markovian arrival process (MAP). It is also assumed that the number of items demanded for the second commodity is a random variable. The ordering policy is to place orders for both commodities when the inventory levels are below prefixed levels for both commodities. The lead time is assumed to have a phase type distribution, and the demands that occur during stock out period are assumed to be lost. The joint probability distribution for both commodities is obtained in the steady state case. Various measures of system performance and the total expected cost rate in the steady state are derived. The results are illustrated with numerical examples.
\end{abstract}

\section{OPSOMMING}

'n Tweeprodukstelsel se voorraad vir klante word kontinu hersien. Die vraag na die produktipes word gekenmerk deur klantvoorkeure. Die versoektempo van klante vir voorraad word aanvaar as 'n Markovproses. Aannames word gemaak oor vraaghoeveelhede en aanlooptyd. Die resultate van die ondersoek word voorgehou via syfervoorbeelde. 


\section{INTRODUCTION}

One of the factors that contribute to the complexity of present day inventory systems is the multitude of items stocked, necessitating multi-commodity inventory systems. In early dealing with such systems, many models were proposed with independently established re-order points. But in situations where several products compete for limited storage space, or share the same transport facility, or are produced on (procured from) the same equipment (supplier), the above strategy overlooks the potential savings associated with joint ordering, and hence will not be optimal. Thus coordinated (also known as joint) replenishment reduces the ordering and setup costs, and allows the user to take advantage of quantity discounts, if any. Various models and references may be found in Miller [23], Agarwal [5], Silver [31], Thomstone and Silver [36], Kalpakam and Arivarignan[15], and Srinivasan and Ravichandran [35]. and further references that they contain.

In continuous review inventory systems, Balintfy [6] and Silver [31] have considered a coordinated re-ordering policy, represented by the triplet $(S, C, s)$, where three parameters, $S_{i}, c_{i}$ and $s_{i}$ are specified for each item $i$ with $s_{i} \leq c_{i} \leq S_{i}$, for a unit sized Poisson demand and constant lead time. In this policy, if the level of the $i$-th commodity at any time is below $s_{i}$, an order is placed for $S_{i}-s_{i}$ items; and at the same time, if any other item $j(\neq i)$ with available inventory is at or below its can-order level $c_{j}$, an order is placed so as to bring its level back to its maximum capacity $S_{j}$. Many subsequent articles have appeared with models involving the above policy. A further article of interest is that of Federgruen et al. [9], which deals with the general case of compound Poisson demands and non-zero lead times.

Throughout the years, the work on methods to solve the joint replenishment problem has been extensive. Readers are referred to the publications of Fung and Ma [10], Goyal [11,12,13], Goyal and Satir [14], Kaspi and Rosenblatt [16], Nilsson et al. [27], Nilsson and Silver [28], Olsen [29], Silver [32], Van Eijs [37], Viswanathan [38,39,40], and Wildeman et al. [41] and references that they contain.

Kalpakam and Arivarignan [15] have introduced an $(s, S)$ policy with a single re-order level $s$ defined in terms of the total number of items in the stock. The policy avoids separate ordering of each commodity. Hence a single processing of orders for both commodities has some advantages in a situation where procurement is made from the same supplies, items are produced on the same machine, or items have to be supplied by the same transport facility.

In the case of two-commodity inventory systems, Anbazhagan and Arivarignan [1,2,3,4] have proposed various ordering policies. Yadavalli et al. [42] have analysed a model with a joint ordering policy and variable order quantities. Sivakumar et al. [33] have considered a two-commodity substitutable inventory system in which the items demanded are delivered after a random time. Sivakumar et al. [34] have considered a two-commodity perishable inventory system with a joint ordering policy.

There are some situations in which a single item is demanded for one commodity and multiple items are demanded for another commodity. For instance, a customer may buy a single razor, or a set of blades, or both. Another example is the sale of a DVD writer and a set of DVDs. It may be noted that the seller would be placing a joint order for both commodities, as these are available from the same source. Moreover, a seller may not be willing to place orders frequently, and may prefer to have one order to replenish stock in a given cycle. These situations are modelled in this work by assuming demand processes that require a single item for one commodity, multiple items for the other commodities, or both commodities, and by assuming a joint re-order for both commodities.

This paper is organised as follows. In section 2, the mathematical model and notations 
followed in the rest of the paper are described. The steady state solution of the joint probability distribution for both commodities, the phase of the demand process, and the phase of the lead time process are given in section 3. In section 4, various measures are derived of system performance in the steady state; and the total expected cost rate is calculated in section 5. Section 6 presents the cost analysis of the model using numerical examples.

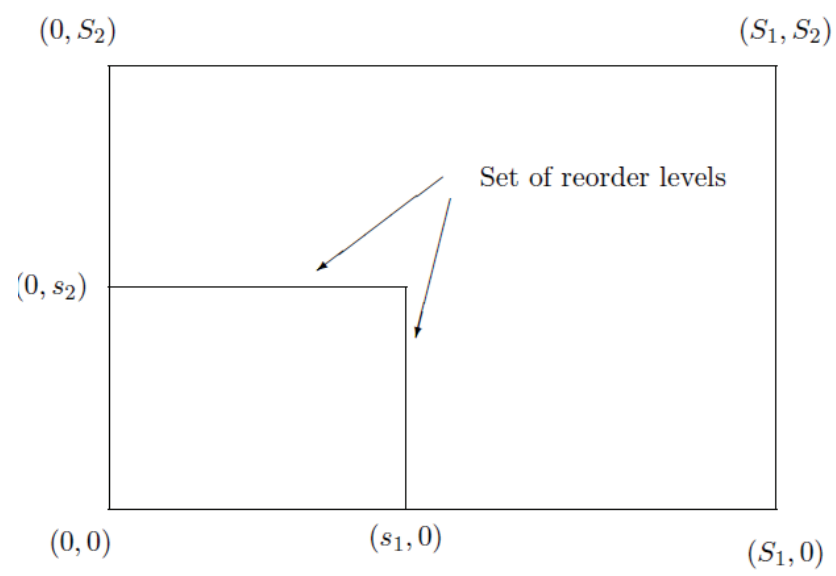

Figure 1: Space of inventory levels

\section{Notations}

0 : zero matrix

$I:$ an identity matrix

$$
\begin{aligned}
& H(x)= \begin{cases}x & \text { if } x>0 \\
0 & \text { if } x \leq 0\end{cases} \\
& E_{i}=\{1,2, \ldots, i\} \\
& E_{i}^{0}=\{0,1, \ldots, i\} \\
& e=\text { a column vector of ones }
\end{aligned}
$$

\section{MODEL DESCRIPTION}

Consider a two-commodity perishable inventory system with the maximum capacity $S_{i}$ units for the $i$-th commodity $(i=1,2)$. Assume that the demand for the first commodity is for a single item and the demand for the second commodity is for bulk items. An arriving customer may demand only the first commodity, or only the second commodity, or both. The number of items demanded for the second commodity at any demand point is a random variable $Y$ with a probability function $p_{k}=\operatorname{Pr}\{Y=k\}, k=1,2,3, \ldots$. The three types of demand for these two commodities occur according to a Markovian arrival process (MAP). The life time of each commodity is exponential with parameter $\gamma_{i}(i=1,2)$. The re-order level for the $i$-th commodity is fixed at $s_{i}\left(1 \leq s_{i} \leq S_{i}\right)$, and the ordering quantity for the $i$-th commodity is $Q_{i}\left(=S_{i}-s_{i}>s_{i}+1\right)$ items when both the inventory levels are less than or equal to their respective re-order levels. Assume that demands during stock-out period are lost, as well as unsatisfied demands. The requirement $S_{i}-s_{i}>s_{i}+1$, ensures that after a replenishment the inventory levels of both commodities will always be above the respective re-order levels. Otherwise it may not be possible to place a re-order (according to the policy), leading to a perpetual shortage. That is, if $L_{i}(t)$ represents inventory level of $i$-th commodity at time $t$, then a re-order is made when $L_{1}(t) \leq s_{1}$ and $L_{2}(t) \leq s_{2}$ (see Figure 1). The time to deliver 
the items is assumed to be of phase type $(P H)$ with representation $(\alpha, T)$ of order $m_{2}$. Note that the phase type distribution is defined as the time until absorption in a finite state irreducible Markov chain with one absorbing state. The mean of the phase type distribution $(\alpha, T)$ is given by $\alpha(-T)^{-1} \mathbf{e}$. Let $\beta$ denote the reciprocal of this mean. That is, $\beta=\left[\alpha(-T)^{-1} \mathbf{e}\right]^{-1}$ gives the rate of replenishment once an order is placed. Let $T^{0}$ be such that $T \mathbf{e}+T^{0}=0$.

For the demand process, the description of MAP as given in Lucantoni [20] was used. Consider a continuous-time Markov chain on the state space $1,2, \ldots, m_{1}$. The demand process is constructively defined as follows. When the chain enters a state $i, 1 \leq i \leq m_{1}$, it remains for an exponential time with parameter $\theta_{i}$. At the end of the sojourn time in state $i$, there are four possible transitions: with probabilities $a_{i j}, 1 \leq j \leq m_{1}$, the chain enters the state $j$ when a demand for the first commodity occurs; with probabilities $b_{i j}, 1 \leq j \leq m_{1}$, the chain enters the state $j$ when a demand for the second commodity occurs; with probabilities $c_{i j}, 1 \leq j \leq m_{1}$, the chain enters the state $j$ when a demand for both commodities occurs; with probabilities $d_{i j}, 1 \leq j \leq m_{1}, i \neq j$, the transitions correspond to no demand and the state of the chain is $j$. The Markov chain can go from state $i$ to state $i$ only through a demand. Defining the square matrices $D_{k}, k=0,1,2,12$, of size $m_{1} \times m_{1}$ by $\left[D_{0}\right]_{i i}=-\theta_{i}$ and $\left[D_{0}\right]_{i j}=\theta_{i} d_{i j}, i \neq j, \quad\left[D_{1}\right]_{i j}=\theta_{i} a_{i j},\left[D_{2}\right]_{i j}=\theta_{i} b_{i j}$ and $\left[D_{12}\right]_{i j}=\theta_{i} c_{i j}, \quad 1 \leq i, j \leq m_{1}$. It is seen that $D=D_{0}+D_{1}+D_{2}+D_{12}$ is an infinitesimal generator of a continuous-time Markov chain. Assume that $D$ is irreducible and $D_{0} e \neq 0$.

Let $\zeta$ be the stationary probability vector of the continuous-time Markov chain with generator $D$. That is, $\zeta$ is the unique probability vector satisfying $\zeta D=0, \zeta e=1$.

Let $\eta$ be the initial probability vector of the underlying Markov chain governing the MAP. By choosing $\eta$ appropriately, the time origin can be modelled to be:

1. an arbitrary arrival point,

2. the end of an interval during which there are at least $k$ arrivals; or

3. the point at which the system is in a specific state, such as when the busy period ends or begins.

The important case is that of the stationary version of the MAP for $\eta=\zeta$. The constant $\lambda=\zeta\left(D_{1}+D_{2}+D_{12}\right) e$, referred to as the fundamental rate, gives the expected number of demands per unit time in the stationary version of the MAP. The quantities $\lambda_{1}=\zeta_{1} e$, $\lambda_{2}=\zeta D_{2} e$ and $\lambda_{12}=\zeta D_{12} e$, give the arrival rate of demand for first commodity, for second commodity, and for both respectively. Note that $\lambda=\lambda_{1}+\lambda_{2}+\lambda_{12}$.

For further details on MAP and phase-type distributions and their usefulness in stochastic modelling, the reader may refer to Chapter 2 in Neuts [24], Chapter 5 in Neuts [25], Ramaswami [30], Lucantoni [20,21], Lucantoni et al. [22], Latouche and Ramaswami [17], Li and Li [19], Lee and Jeon [18], Chakravarthy and Dudin [8], and references therein for a detailed introduction of the MAP and phase-type distribution. Some recent reviews can be found in Neuts [26] and Chakravarthy [7].

Let $J_{1}(t)$ and $J_{2}(t)$ respectively denote the phase of the demand process and the phase of 
the lead time process. Then the stochastic process $\left\{\left(L_{1}(t), L_{2}(t), J_{1}(t), J_{2}(t)\right), t \geq 0\right\}$ has the state space,

$$
\begin{aligned}
& \Omega=\left\{\left(i_{1}, i_{2}, i_{3}, 0\right), i_{1} \in E_{S_{1}} \backslash E_{s_{1}, i_{2}} \in E_{S_{2}} \backslash E_{s_{2}}, i_{3} \in E_{m_{1}}\right\} \\
& \cup\left\{\left(i_{1}, i_{2}, i_{3}, 0\right), i_{1} \in E_{S_{1}} \backslash E_{s_{1}}, i_{2} \in E_{S_{2}}^{0}, i_{3} \in E_{m_{1}}\right\} \\
& \cup\left\{\left(i_{1}, i_{2}, i_{3}, 0\right), i_{1} \in E_{s_{1}}^{0}, \in E_{S_{2}} \backslash E_{s_{2}}, i_{3} \in E_{m_{1}}\right\} \\
& \cup\left\{\left(i_{1}, i_{2}, i_{3}, i_{4}\right), i_{1} \in E_{s_{1}}^{0}, i_{2} \in E_{s_{2}}^{0}, i_{3} \in E_{m_{1}}, i_{4} \in E_{m_{2}}\right\}
\end{aligned}
$$

From the assumptions made on the demand and replenishment processes, it can be shown that $\left\{\left(L_{1}(t), L_{2}(t), J_{1}(t), J_{2}(t)\right), t \geq 0\right\}$ is a Markov process on the state space $\Omega$. By placing the sets of state space in lexicographic order, the infinitesimal generator of the Markov chain governing the system, in block partitioned form, is given by

$$
[P]_{i j}=\left\{\begin{array}{lll}
A_{i}, & j=i, & i=0,1, \ldots, S_{1}, \\
B_{i}, & j=i-1, & i=1,2, \ldots, S_{1}, \\
C, & j=i+Q_{1}, & i=0,1, \ldots, s_{1}, \\
0, & \text { otherwise. } &
\end{array}\right.
$$

where

$[C]_{i j}= \begin{cases}I_{m_{1}} \otimes T^{0}, & j=i+Q_{2}, \quad i=0,1, \ldots, s_{2}, \\ 0, & \text { otherwise. }\end{cases}$

For $k=s_{1}+2, s_{1}+3, \ldots, s_{1}$,

$\left[B_{k}\right]_{i j}=\left\{\begin{array}{lll}D_{1}+k \gamma_{1} I_{m_{1}}, & j=i, & i=1,2, \ldots, S_{2}, \\ D_{1}+D_{12}+k \gamma_{1} I_{m_{1}}, & j=i, & i=0, \\ p_{i-j} D_{12}, & j=1,2, \ldots, i-1, & i=2,3, \ldots, S_{2}, \\ p_{i} D_{12}, & j=0, & i=1,2, \ldots, S_{2}, \\ 0, & \text { otherwise. } & \end{array}\right.$

$$
p_{n}^{\prime}=\sum_{i=n}^{\infty} p_{i}
$$

For $k=s_{1}+1$,

$$
\left[B_{k}\right]_{i j}=\left\{\begin{array}{lll}
D_{1}+k \gamma_{1} I_{m_{1}}, & j=i, & i=s_{2}+1, s_{2}+2, \ldots, S_{2}, \\
\left(D_{1}+k \gamma_{1} I_{m_{1}}\right) \otimes \alpha, & j=i, & i=1,2, \ldots, s_{2}, \\
\left(D_{1}+D_{12}+k \gamma_{1} I_{m_{1}}\right) \otimes \alpha, & j=i, & i=0, \\
p_{i-j} D_{12}, & j=s_{2}+1, s_{2}+2, \ldots, i-1, & i=s_{2}+2, s_{2}+3, \ldots, S_{2}, \\
p_{i-j} D_{12} \otimes \alpha, & j=1,2, \ldots, s_{2}, & i=s_{2}+2, s_{2}+3, \ldots, S_{2}, \\
& \text { or } & \\
& j=1,2, \ldots, i-1, & i=2,3, \ldots, s_{2}+1, \\
p_{i} D_{12} \otimes \alpha, & j=0, & i=1,2, \ldots, S_{2}, \\
0, & \text { otherwise. }
\end{array}\right.
$$


For $k=1,2, \ldots, s_{1}$

$\left[B_{k}\right]_{i j}=\left\{\begin{array}{lll}D_{1}+k \gamma_{1} I_{m_{1}}, & j=i, & i=s_{2}+1, s_{2}+2, \ldots, S_{2}, \\ \left(D_{1}+k \gamma_{1} I_{m_{1}}\right) \otimes I_{m_{2}}, & j=i, & i=1,2, \ldots, s_{2}, \\ \left(D_{1}+D_{12}+k \gamma_{1} I_{m_{1}}\right) \otimes I_{m_{2}}, & j=i, & i=0, \\ p_{i-j} D_{12}, & j=s_{2}+1, s_{2}+2, \ldots, i-1, & i=s_{2}+2, s_{2}+3, \ldots, S_{2}, \\ p_{i-j} D_{12} \otimes \alpha, & j=1,2, \ldots, s_{2}, & i=s_{2}+1, s_{2}+2, \ldots, S_{2}, \\ p_{i}^{\prime} D_{12} \otimes \alpha, & j=0, & i=s_{2}+1, s_{2}+2, \ldots, S_{2}, \\ p_{i-j} D_{12} \otimes I_{m_{2}}, & j=1,2, \ldots, i-1, & i=2,3, \ldots, s_{2}, \\ p_{i}^{\prime} D_{12} \otimes I_{m_{2}}, & j=0, & i=1,2, \ldots, s_{2}, \\ 0, & \text { otherwise. }\end{array}\right.$

For $k=s_{1}+1, s_{1}+2, \ldots, S_{1}$,

$\left[A_{k}\right]_{i j}=\left\{\begin{array}{lll}p_{1} D_{2}+k \gamma_{2} I_{m_{1}}, & j=i-1, & i=2,3, \ldots, S_{2}, \\ p_{i-j} D_{2}, & j=1,2, \ldots, i-2, & i=3,4, \ldots, S_{2}, \\ p_{i}^{\prime} D_{2}, & j=0, & i=1,2, \ldots, S_{2}, \\ D_{0}-\left(k \gamma_{1}+i \gamma_{1}\right) I_{m_{1}} & j=i, & i=1,2, \ldots, S_{2}, \\ D_{0}+D_{2}-k \gamma_{1} I_{m_{1}}, & j=i, & i=0, \\ 0, & \text { otherwise. } & \end{array}\right.$

For $k=1,2, \ldots, s_{1}$

$\left[A_{k}\right]_{i j}=\left\{\begin{array}{lll}p_{1} D_{2}+i \gamma_{2} I_{m_{1}}, & j=i-1, & i=s_{2}+2, s_{2}+3, \ldots, S_{2}, \\ \left(p_{1} D_{2}+i \gamma_{2} I_{m_{1}}\right) \otimes \alpha, & j=i-1, & i=s_{2}+1, \\ \left(p_{1} D_{2}+i \gamma_{2} I_{m_{1}}\right) \otimes I_{m_{2}}, & j=i-1, & i=2,3, \ldots, s_{2}, \\ p_{i-j} D_{2}, & j=s_{2}+1, s_{2}+2, \ldots, i-2, & i=s_{2}+3, s_{2}+4, \ldots, S_{2}, \\ p_{i-j} D_{2} \otimes \alpha, & j=1,2, \ldots, i-2, & i=s_{2}+1, s_{2}+2, \\ & \multicolumn{1}{c}{\text { or }} & \\ p_{i-j} D_{2} \otimes I_{m_{2}}, & j=1,2, \ldots, s_{2}, & i=s_{2}+3, s_{2}+4, \ldots, S_{2}, \\ p_{i}^{\prime} D_{2} \otimes \alpha, & j=1,2, \ldots, i-2, & i=3,4, \ldots, s_{2}, \\ p_{i}^{\prime} D_{2} \otimes I_{m_{2}}, & j=0, & i=s_{2}+1, s_{2}+2, \ldots, S_{2}, \\ D_{0}-\left(k \gamma_{1}+i \gamma_{2}\right) I_{m_{1}}, & j=0, & i=1,2, \ldots, s_{2}, \\ D_{0} \oplus T-\left(k \gamma_{1}+i \gamma_{2}\right) I_{m_{1}} \otimes I_{m_{2}}, & j=i, & i=s_{2}+1, s_{2}+2, \ldots, S_{2}, \\ \left(D_{0}+D_{2}\right) \oplus T-k \gamma_{1} I_{m_{1}} \otimes I_{m_{2}}, & j=i, & i=1,2, \ldots, s_{2}, \\ 0, & \text { otherwise. } & i=0,\end{array}\right.$


For $k=0$,

$\left[A_{k}\right]_{i j}=\left\{\begin{array}{lll}p_{1}\left(D_{2}+D_{12}\right)+i \gamma_{2} I_{m_{1}}, & j=i-1, & i=s_{2}+2, s_{2}+3, \ldots, S_{2}, \\ \left(p_{1}\left(D_{2}+D_{12}\right)+i \gamma_{2} I_{m_{1}}\right) \otimes \alpha, & j=i-1, & i=s_{2}+1, \\ \left(p_{1}\left(D_{2}+D_{12}\right)+i \gamma_{2} I_{m_{1}}\right) \otimes I_{m_{2}}, & j=i-1, & i=2,3, \ldots, s_{2}, \\ p_{i-j}\left(D_{2}+D_{12}\right), & j=s_{2}+1, s_{2}+2, \ldots, i-2, & i=s_{2}+3, s_{2}+4, \ldots, S_{2}, \\ p_{i-j}\left(D_{2}+D_{12}\right) \otimes \alpha, & j=1,2, \ldots, i-2, & i=s_{2}+1, s_{2}+2, \\ \multicolumn{1}{c}{\text { or }} & \\ p_{i-j}\left(D_{2}+D_{12}\right) \otimes I_{m_{2}}, & j=1,2, \ldots, s_{2}, & i=s_{2}+3, s_{2}+4, \ldots, S_{2}, \\ p_{i}^{\prime}\left(D_{2}+D_{12}\right) \otimes \alpha, & j=1,2, \ldots, i-2, & i=3,4, \ldots, s_{2}, \\ p_{i}^{\prime}\left(D_{2}+D_{12}\right) \otimes I_{m_{2}}, & j=0, & i=s_{2}+1, s_{2}+2, \ldots, S_{2}, \\ D_{0}+D_{1}-\left(i \gamma_{2}\right) I_{m_{1}}, & j=0, & i=1,2, \ldots, s_{2}, \\ \left(D_{0}+D_{1}\right) \oplus T-\left(i \gamma_{2}\right) I_{m_{1}} \otimes I_{m_{2}}, & j=i, & i=s_{2}+1, s_{2}+2, \ldots, S_{2}, \\ D \oplus T, & j=i, & i=1,2, \ldots, s_{2}, \\ 0, & \text { otherwise. } & i=0,\end{array}\right.$

It may be noted that the matrix $C$ is of order $\left(Q_{1} m_{1}+\left(s_{1}+1\right) m_{1} m_{2}\right) \times\left(S_{2}+1\right) m_{1}$, the matrices $B_{i}, i=s_{1}+2, s_{1}+3, \ldots, S_{1}$, are of order $\left(S_{2}+1\right) m_{1} \times\left(S_{2}+1\right) m_{1}$, the matrix $B_{s_{1}+1}$ is of order $\left(S_{2}+1\right) m_{1} \times\left(Q_{1} m_{1}+\left(s_{1}+1\right) m_{1} m_{2}\right)$, the matrices $B_{i}, i=1,2, \ldots, s_{1}$, are of order $\left(Q_{1} m_{1}+\left(s_{1}+1\right) m_{1} m_{2}\right) \times\left(Q_{1} m_{1}+\left(s_{1}+1\right) m_{1} m_{2}\right)$, the matrices $A_{i}, i=0,1, \ldots, s_{1}$ are of order $\left(Q_{1} m_{1}+\left(s_{1}+1\right) m_{1} m_{2}\right) \times\left(Q_{1} m_{1}+\left(s_{1}+1\right) m_{1} m_{2}\right)$, and the matrices $A_{i}, i=s_{1}+1, s_{1}+2 \ldots, S_{1}$ are of order $\left(S_{2}+1\right) m_{1} \times\left(S_{2}+1\right) m_{1}$.

\section{STEADY STATE ANALYSIS}

It can be seen from the structure of $P$ that the homogeneous Markov process $\left\{\left(L_{1}(t), L_{2}(t), J_{1}(t), J_{2}(t)\right), t \geq 0\right\}$ on the finite state space $\Omega$ is irreducible.

Hence, the limiting distribution $\phi_{\left(i, k, j_{1}, j_{2}\right)}=$

$\lim _{t \rightarrow \infty} \operatorname{Pr}\left[L_{1}(t)=i, L_{2}(t)=k, J_{1}(t)=j_{1}, J_{2}(t)=j_{2} \mid L_{1}(0), L_{2}(0), J_{1}(0), J_{2}(0)\right]$

exists. Let

$\phi_{\left(i, k, j_{1}\right)}= \begin{cases}\left(\phi_{\left(i, k, j_{1}, 1\right)}, \phi_{\left(i, k, j_{1}, 2\right)}, \ldots, \phi_{\left(i, k, j_{1}, m_{2}\right)}\right), & \left(i, k, j_{1}\right) \in F_{1}, \\ \left(\phi_{\left(i, k, j_{1}, 0\right)}\right), & \left(i, k, j_{1}\right) \in F_{2},\end{cases}$

where

$F_{1}=\left\{\left(i_{1}, i_{2}, i_{3}\right), i_{1} \in E_{s_{1}}^{0}, i_{2} \in E_{s_{2}}^{0}, i_{3} \in E_{m_{1}}\right\}$

$F_{2}=\left\{\left(i_{1}, i_{2}, i_{3}\right), i_{1} \in E_{s_{1}} \backslash E_{s_{1}}, i_{2} \in E_{s_{2}} \backslash E_{s_{2}}, i_{3} \in E_{m_{1}}\right\}$

$\cup\left\{\left(i_{1}, i_{2}, i_{3}\right), i_{1} \in E_{s_{1}} \backslash E_{s_{1}}, i_{2} \in E_{s_{2}}^{0}, i_{3} \in E_{m_{1}}\right\}$

$\cup\left\{\left(i_{1}, i_{2}, i_{3}\right), i_{1} \in E_{s_{1}}^{0}, \in E_{s_{2}} \backslash E_{s_{2}}, i_{3} \in E_{m_{1}}\right\}$

$\phi_{(i, k)}=\left(\phi_{(i, k, 1)}, \phi_{(i, k, 2)}, \ldots, \phi_{\left(i, k, m_{1}\right)}\right), k \in E_{2}, i \in E_{1}$,

$\phi^{(i)}=\left\{\left(\phi_{(i, 0)}, \phi_{(i, 1)}, \ldots, \phi_{\left(i, S_{2}\right)}\right), \quad i \in E_{1}\right.$ 
and

$\Phi=\left(\Phi^{(0)}, \Phi^{(1)}, \ldots, \Phi^{\left(S_{1}\right)}\right)$.

Then the vector of limiting probabilities $\Phi$ satisfies

$\Phi P=0 \quad$ and $\quad \Phi \mathbf{e}=1$.

The first equation of the above yields the following set of equations:

$$
\begin{aligned}
& \Phi^{(i+1)} B_{i+1}+\Phi^{(i)} A_{i}=0, i=0,1, \ldots, Q_{1}-1, \\
& \Phi^{(i+1)} B_{i+1}+\Phi^{(i)} A_{i}+\Phi^{\left(i-Q_{1}\right)} C=0, i=Q_{1}, \\
& \Phi^{(i+1)} B_{i+1}+\Phi^{(i)} A_{i}+\Phi^{\left(i-Q_{1}\right)} C=0, i=Q_{1}+1, Q_{1}+2, \ldots, S_{1}-1, \\
& \Phi^{(i)} A_{i}+\Phi^{\left(i-Q_{1}\right)} C=0, i=S_{1} .
\end{aligned}
$$

The equations (except (2)) can be recursively solved to obtain

$$
\Phi^{(i)}=\Phi^{\left(Q_{1}\right)} \theta_{i}, \quad i=0,1, \ldots, S_{1},
$$

where

$$
\theta_{i}=\left\{\begin{array}{c}
(-1)^{Q_{1}-i} B_{Q_{1}} A_{Q_{1}-1}^{-1} B_{Q_{1}-1} \cdots B_{i+1} A_{i}^{-1}, \quad i=0,1, \ldots, Q_{1}-1, \\
I, \quad i=Q_{1}, \\
(-1)^{2 Q_{1}-i+1} \sum_{j=0}^{S-i}\left[\left(B_{Q_{1}} A_{Q_{1}-1}^{-1} B_{Q_{1}-1} \cdots B_{s_{1}+1-j} A_{s_{1}-j}^{-1}\right)\right. \\
\left.\quad\left(B_{S_{1}-j} A_{S_{1}-j-1}^{-1} B_{S_{1}-j-1} \cdots B_{S_{1}} A_{S_{1}-j}^{-1}\right)\right], \quad i=Q_{1}+1, \ldots, S_{1} .
\end{array}\right.
$$

Substituting the values of $\theta_{i}$ in equation (2) and in the normalising condition, it follows that

$$
\begin{aligned}
& \Phi^{\left(Q_{1}\right)}\left[( - 1 ) ^ { Q _ { 1 } } \sum _ { j = 0 } ^ { s - 1 } \left[\left(B_{Q_{1}} A_{Q_{1}-1}^{-1} B_{Q_{1}-1} \cdots B_{s_{1}+1-j} A_{s_{1}-j}^{-1}\right) C A_{s_{1}-j}^{-1}\left(B_{s_{1}-j} A_{s_{1}-j-1}^{-1} B_{s_{1}-j-1} \cdots B_{Q_{1}+2} A_{Q_{1}+1}^{-1}\right) \mid B_{Q_{1}+1}+A_{Q_{1}}\right.\right. \\
& \left.+(-1)^{Q_{1}} B_{Q_{1}} A_{Q_{1}-1}^{-1} B_{Q_{1}-1} \cdots B_{1} A_{0}^{-1} C\right]=0
\end{aligned}
$$

and

$$
\begin{aligned}
& \Phi^{\left(Q_{1}\right)}\left[\sum_{i=0}^{Q_{1}-1}\left((-1)^{Q_{1}-i} B_{Q_{1}} A_{Q_{1}-1}^{-1} B_{Q_{1}-1} \cdots B_{i+1} A_{i}^{-1}\right)+l\right. \\
& +\sum_{i=Q_{1}+1}^{S_{1}}\left(( - 1 ) ^ { 2 Q _ { 1 } - i + 1 } \sum _ { j = 0 } ^ { S - i } \left[\left(B_{Q_{1}} A_{Q_{1}-1}^{-1} B_{Q_{1}-1} \cdots B_{s_{1}+1-j} A_{s_{1}-j}^{-1}\right) C A_{s_{1}-j}^{-1}\right.\right. \\
& \left.\left.\left.\left(B_{S_{1}-j} A_{S_{1}-j-1}^{-1} B_{S_{1}-j-1} \cdots B_{i+1} A_{i}^{-1}\right)\right]\right)\right] e=1 .
\end{aligned}
$$

From the equation (6), the value of $\Phi^{(Q)}$ may be obtained up to a constant multiplication. This constant can be determined by substituting the value of $\Phi^{(Q)}$ in the equation (7). Substituting the value of $\Phi^{(Q)}$ in the equation (5) we get the values of $\Phi^{(i)}, i=0,1, \ldots, S$. 


\section{SYSTEM PERFORMANCE MEASURES}

In this section, certain stationary performance measures of the system are derived. Using these measures, the total expected cost per unit time may be determined.

\subsection{Mean inventory level}

Let $\eta_{l_{k}}$ denote the mean inventory level of $k$-th commodity in the steady state $(k=1,2)$ Since $\phi_{(i, j)}$ is the steady state probability vector for the inventory level of first commodity $i$ and the second commodity $j$, it follows that

$\eta_{l_{1}}=\sum_{i=1}^{S_{1}} \sum_{j=0}^{S_{2}} j \phi_{(i, j)} \mathbf{e}$.

and

$\eta_{l_{2}}=\sum_{i=0}^{s_{1}} \sum_{j=1}^{s_{2}} j \phi_{(i, j)} \mathbf{e}$

\subsection{Mean re-order rate}

A re-order for both commodities is made when the joint inventory level drops to $\left(s_{1}, s_{2}\right)$ or $\left(s_{1}, j\right), j<s_{2}$ or $\left(i, s_{2}\right), i<s_{1}$. Let $\eta_{R}$ denote the mean re-order rate for both commodities in the steady state, given by

$$
\begin{aligned}
& \eta_{R}=\sum_{k=0}^{s_{1}} \sum_{j=1}^{Q_{2}} \phi_{\left(k, s_{2}+j\right)} \sum_{u=j}^{\infty} p_{u}\left(D_{2} \otimes \alpha\right) \mathbf{e}+\sum_{k=0}^{s_{2}} \phi_{\left(s_{1}+1, k\right)}\left(D_{1} \otimes \alpha\right) \mathbf{e} \\
& +\sum_{k=1}^{s_{1}+1 Q_{2}} \sum_{j=1} \phi_{\left(k, s_{2}+j\right)} \sum_{u=j}^{\infty} p_{u}\left(D_{12} \otimes \alpha\right) \mathbf{e}+\sum_{k=0}^{s_{1}}\left(s_{2}+1\right) \gamma_{2} \phi_{\left(k, s_{2}+1\right)} \mathbf{e} \\
& +\sum_{k=0}^{s_{2}}\left(s_{1}+1\right) \gamma_{1} \phi_{\left(s_{1}+1, k\right)} \mathbf{e} .
\end{aligned}
$$

\subsection{Mean shortage rate}

Let $\eta_{S h_{i}}$ denote the mean shortage rate of $i$-th type demand in the steady state $(i=1,2,12)$. Consequently

$\eta_{S h_{1}}=\sum_{k=0}^{s_{2}} \phi_{(0, k)} D_{1} \mathbf{e}$

$\eta_{S h_{2}}=\sum_{i=0}^{S_{1}} \sum_{j=0}^{S_{2}} \phi_{(i, j)} \sum_{k=j+1}^{\infty} p_{k} D_{2} \mathbf{e}$

and

$\eta_{S h_{12}}=\left(\sum_{k=0}^{S_{2}} \phi_{(0, k)} D_{12} \mathbf{e}+\sum_{i=0}^{S_{1}} \sum_{j=0}^{S_{2}} \phi_{(i, j)} \sum_{k=j+1}^{\infty} p_{k} D_{12} \mathbf{e}\right)$.

\subsection{Mean failure rate}

Let the mean failure rate of commodity- $i$ in the steady state be denoted by $\eta_{F_{i}},(i=1,2)$. A failure occurs when any one of the stocked items ceases to function or perishes. Since the rate of failure of a single item is $\gamma_{j}$ for commodity $j$, the rate at which any one of $i$ items for the $j$-th commodity fail is given by $i \gamma_{j},(j=1,2)$. When the process is in state $\left(i, k, j_{1}, j_{2}\right)$, 
the rate of failure of any one item of the first commodity is given by $i \gamma_{1}$ (provided $i>0$ ), and the failure rate of any one item of the second commodity is $k \gamma_{2}$ (provided $k>0$ ).

Then we have

$\eta_{F_{1}}=\sum_{i=1}^{s_{1}} \sum_{k=0}^{s_{2}} i \gamma_{1} \phi_{(i, k)}$ e.

and

$\eta_{F_{2}}=\sum_{i=0}^{s_{1}} \sum_{k=1}^{s_{2}} k \gamma_{2} \phi_{(i, k)} \mathbf{e}$

\section{COST ANALYSIS}

The total expected cost per unit time (total expected cost rate) in the steady-state for this model is defined to be

$T C\left(S_{1}, s_{1}, S_{2}, s_{2}\right)=c_{h_{1}} \eta_{l_{1}}+c_{h_{2}} \eta_{l_{2}}+c_{s} \eta_{R}+c_{s h_{1}} \eta_{s h_{1}}+c_{s h_{2}} \eta_{s h_{2}}+c_{s h_{12}} \eta_{s h_{12}}+c_{f_{1}} \eta_{F_{1}}+c_{f_{2}} \zeta_{F_{2}}$

where

$c_{h_{i}}$ : The inventory carrying cost of $i$-th commodity per unit item per unit time $(i=1,2)$.

$c_{s}:$ Joint ordering cost per order.

$c_{f_{i}}$ : The failure cost of $i$-th commodity per unit item per unit time $(i=1,2)$.

$c_{s h_{i}}$ : Shortage cost due to type $i$ demand per unit time $(i=1,2,12)$.

Since the total expected cost rate is only implicitly known, the analytical properties - such as convexity of the total expected cost rate - cannot be carried out in the present form. However, the following numerical examples to demonstrate the computability of the results derived in our work, and to illustrate the existence of local optima when the total cost function is treated as a function of only two variables, are presented.

\section{ILLUSTRATIVE NUMERICAL EXAMPLES}

Since the total expected cost rate is obtained in a complex form, the convexity of the total expected cost rate cannot be studied by analytical methods. Hence, 'simple' numerical search procedures are used to find the 'local' optimal values for any two of the decision variables $\left\{S_{1}, S_{1}, S_{2}, S_{2}\right\}$ by considering a small set of integer values for these variables. With a large number of numerical examples, it has been found that the total cost rate per unit time in the long run is either a convex function of both variables or an increasing function of any one variable.

The following five MAPS for arrival of demands are considered, and it may be noted that these processes can be normalized to have a specific (given) demand rate $\lambda$ when considered for arrival of demands.

\section{Exponential (Exp)}

$H_{0}=(-1) H_{1}=(1)$

\section{Erlang (Erl)}

$$
H_{0}=\left(\begin{array}{ccc}
-1 & 1 & 0 \\
0 & -1 & 1 \\
0 & 0 & -1
\end{array}\right) \quad H_{1}=\left(\begin{array}{lll}
0 & 0 & 0 \\
0 & 0 & 0 \\
1 & 0 & 0
\end{array}\right)
$$




\section{Hyper-exponential (HExp)}

$$
H_{0}=\left(\begin{array}{rr}
-10 & 0 \\
0 & -1
\end{array}\right) \quad H_{1}=\left(\begin{array}{rr}
9 & 1 \\
0.9 & 0.1
\end{array}\right)
$$

4. MAP with negative correlation (MNC)

$$
H_{0}=\left(\begin{array}{rrr}
-2 & 2 & 0 \\
0 & -81 & 0 \\
0 & 0 & -81
\end{array}\right) \quad H_{1}=\left(\begin{array}{rrr}
0 & 0 & 0 \\
25.25 & 0 & 55.75 \\
55.75 & 0 & 25.25
\end{array}\right)
$$

\section{MAP with positive correlation (MPC)}

$$
H_{0}=\left(\begin{array}{rrr}
-2 & 2 & 0 \\
0 & -81 & 0 \\
0 & 0 & -81
\end{array}\right) \quad H_{1}=\left(\begin{array}{rrr}
0 & 0 & 0 \\
55.25 & 0 & 25.75 \\
25.75 & 0 & 55.25
\end{array}\right)
$$

All the above MAPS are qualitatively different in that they have different variance and correlation structures. The first three processes are special cases of renewal processes, and the correlation between arrival times is 0 . The demand process labelled as MNC has correlated arrivals with a correlation coefficient of -0.1254 , and the demands corresponding to the process labelled MPC have a positive correlation coefficient of 0.1213 . Since Erlang has the least variance among the five arrival processes considered here, the ratios of the variances of the other four arrival processes, labelled Exp, HExp, MNC and MPC above, with respect to the Erlang process, are 3.0, 15.1163, 8.1795, 8.1795 respectively. The ratios are given rather than the actual values, since the variance depends on the arrival rate, which is varied in the discussion.

For the lead time distribution, the following three $P H$ - distributions are considered. Again these processes can be normalised to have a specific (given) rate $\beta$ when considered for replenishment.

\section{Exponential (Exp)}

$\alpha=(1) T=(-1)$

\section{Erlang (Erl)}

$$
\alpha=(1,0,0,0) T=\left(\begin{array}{rrrr}
-1 & 1 & 0 & 0 \\
0 & -1 & 1 & 0 \\
0 & 0 & -1 & 1 \\
0 & 0 & 0 & -1
\end{array}\right)
$$

\section{Hyper-exponential (HExp)}

$$
\alpha=(0.9,0.1) T=\left(\begin{array}{cc}
-10 & 0 \\
0 & -1
\end{array}\right)
$$

Example 1: In this example, the effect of the demand rate $\lambda$, the lead time rate $\beta$, the five types of demand processes, and the three types of lead time processes on the optimal values $\left(S_{1}^{*}, S_{2}^{*}\right)$ and the optimal cost rate $T C\left(S_{1}^{*}, 2, S_{2}^{*}, 4\right)$ is illustrated. The following fixed values for the parameters and costs are assumed:

$$
\begin{aligned}
& D_{0}=H_{0}, D_{1}=0.3 H_{1}, D_{2}=0.4 H_{1}, D_{12}=0.3 H_{1}, \gamma_{1}=0.8, \gamma_{2}=0.6, p_{i}=0.6 * 0.4^{i-1}, i=1,2, \ldots, \\
& c_{h_{1}}=0.05, c_{h_{2}}=0.01, c_{s}=10, c_{s h_{1}}=0.8, c_{s h_{2}}=1.5, c_{s h_{12}}=1, c_{f_{1}}=0.2, c_{f_{2}}=0.2 .
\end{aligned}
$$


Table 1 gives the optimum values, $S_{1}^{*}$ and $S_{2}^{*}$, that minimise the total expected cost rate for each of the five MAPs for arrivals of demands considered against each of the three $\mathrm{PHs}$ for lead times. The associated total expected cost rate values are also given in the table. The lower entry in each cell gives the optimal expected cost rate, and the upper entries correspond to $S_{1}^{*}$ and $S_{2}^{*}$. The following observations from Table 1 may be noticed:

1. As $\lambda$ increases, the optimal total cost rate decreases for all five demand processes and for all three lead time processes. Similarly, as $\beta$ increases the optimal total cost rate decreases.

2. The optimal total expected cost rate has a higher value for a demand process having an hyper-exponential distribution, and a lower value for the Erlang demand process.

3. The Erlang distributed lead time has a low optimal total cost rate, except for an HExp distributed demand process; and HExp distributed lead time has high optimal total cost rate, except for HExp distributed demand process. For HExp distributed demand process this observation reverses - i.e. HExp distributed lead time has a low optimal total cost rate, and Erl distributed lead time has a high optimal total cost rate.

Example 2: In this example, the effect of the arrival rate $\lambda$, the lead time rate $\beta$, and the type of arrival and lead time processes on the optimal values $\left(s_{1}^{*}, s_{2}^{*}\right)$ and optimal cost rate $T C\left(15, s_{1}^{*}, 30, s_{2}^{*}\right)$ is illustrated. Assume the following fixed values for the parameters and cost:

$$
\begin{aligned}
& D_{0}=H_{0}, D_{1}=0.3 H_{1}, D_{2}=0.4 H_{1}, D_{12}=0.3 H_{1}, \gamma_{1}=0.6, \gamma_{2}=0.5, p_{i}=0.55^{*} 0.45^{i-1}, i=1,2, \ldots, \\
& c h_{1}=0.01, c h_{2}=0.01, c_{s}=10, c_{s h_{1}}=0.8, c_{s h_{2}}=1.5, c_{s h_{12}}=1, c_{f_{1}}=0.2, c_{f_{2}}=0.2 .
\end{aligned}
$$

The optimum values $s_{1}^{*}$ and $s_{2}^{*}$ that minimise the expected total cost for each of the five $M A P S$ for arrivals of demands considered against each of the three $P H s$ for lead times is given in Table 2 . The associated total expected cost rate values are also given. The lower entry in each cell gives the optimal expected cost rate, and the upper entries correspond to

\begin{tabular}{|c|c|c|c|c|c|c|c|c|}
\hline \multicolumn{9}{|c|}{ Lead time distribution } \\
\hline \multirow{22}{*}{$\begin{array}{c}\text { MAP } \\
\text { demands } \\
\text { distributions }\end{array}$} & $\beta$ & & \multicolumn{3}{|c|}{10} & \multicolumn{3}{|c|}{15} \\
\hline & $\lambda$ & & Exp & Erl & HExp & $\operatorname{Exp}$ & Erl & HExp \\
\hline & \multirow{10}{*}{6} & Exp & $(13,46)$ & $(13,46)$ & $(13,46)$ & $(13,47)$ & $(13,47)$ & $(13,47)$ \\
\hline & & & 8.0236 & 8.0177 & 8.0277 & 8.2027 & 8.1999 & 8.2047 \\
\hline & & Erl & $(13,46)$ & $(13,46)$ & $(13,46)$ & $(13,47)$ & $(13,47)$ & $(13,47)$ \\
\hline & & & 7.9967 & 7.9905 & 8.0009 & 8.1838 & 8.1809 & 8.1858 \\
\hline & & HExp & $(13,46)$ & $(13,46)$ & $(13,46)$ & $(13,47)$ & $(13,47)$ & $(13,47)$ \\
\hline & & & 8.1568 & 8.1570 & 8.1567 & 8.2977 & 8.2978 & 8.2976 \\
\hline & & MNC & $(13,46)$ & $(13,46)$ & $(13,46)$ & $(13,47)$ & $(13,47)$ & $(13,47)$ \\
\hline & & & 8.0736 & 8.0680 & 8.0774 & 8.2379 & 8.2352 & 8.2397 \\
\hline & & MPC & $(13,46)$ & $(13,46)$ & $(13,46)$ & $(13,47)$ & $(13,47)$ & $(13,47)$ \\
\hline & & & 8.1267 & 8.1214 & 8.1303 & 8.2753 & 8.2727 & 8.2770 \\
\hline & \multirow{10}{*}{8} & Exp & $(17,58)$ & $(17,58)$ & $(17,58)$ & $(18,60)$ & $(18,60)$ & $(18,60)$ \\
\hline & & & 10.5224 & 10.5175 & 10.5258 & 10.8125 & 10.8101 & 10.8141 \\
\hline & & Erl & $(17,58)$ & $(17,58)$ & $(17,58)$ & $(18,60)$ & $(18,60)$ & $(18,60)$ \\
\hline & & & 10.4959 & 10.4908 & 10.4994 & 10.7939 & 10.7915 & 10.7956 \\
\hline & & HExp & $(17,58)$ & $(17,58)$ & $(17,58)$ & $(17,59)$ & $(17,59)$ & $(18,60)$ \\
\hline & & & 10.6604 & 10.6608 & 10.6601 & 10.9104 & 10.9106 & 10.9103 \\
\hline & & MNC & $(17,58)$ & $(17,58)$ & $(17,58)$ & $(18,60)$ & $(18,60)$ & $(18,60)$ \\
\hline & & & 10.5717 & 10.5670 & 10.5749 & 10.8470 & 10.8448 & 10.8486 \\
\hline & & MPC & $(17,58)$ & $(17,58)$ & $(17,58)$ & $(18,60)$ & $(18,60)$ & $(18,60)$ \\
\hline & & & 10.6260 & 10.6215 & 10.6291 & 10.8852 & 10.8830 & 10.8867 \\
\hline
\end{tabular}
$s_{1}^{*}$ and $s_{2}^{*}$. The key observations are summarised below.

Table 1: Total expected cost rate as a function of $\left(S_{1}, S_{2}\right)$ 
1. As $\lambda$ increases, the optimal total cost rate increases, except for an HExp distributed demand process. For an HExp distributed demand process, the optimal total cost rate decreases as the demand rate $\lambda$ increases.

2. When $\beta$ increases, the optimal total cost rate increases for all combinations of five arrival processes and three demand processes.

3. The optimal cost rate is high in cases where the demand process is an HExp, and it is low when the demand process is Erlang.

4. The optimal total cost rate is low when the lead time is Erl, except for the HExp distributed demand process. For HExp distributed lead time, the optimal total cost rate is high, except for HExp distributed demand process. For HExp distributed demand process this observation reverses - i.e. the HExp distributed lead time is associated with a low optimal total cost rate, and Erl is associated with a high optimal total cost rate.

\begin{tabular}{|c|c|c|c|c|c|c|c|c|}
\hline \multicolumn{9}{|c|}{ Lead time distribution } \\
\hline \multirow{22}{*}{$\begin{array}{c}\text { MAP } \\
\text { Demands } \\
\text { Distri- } \\
\text { butions }\end{array}$} & $\beta$ & & & 10 & & & 15 & \\
\hline & $\lambda$ & & Exp & Erl & HExp & Exp & Erl & HExp \\
\hline & \multirow{10}{*}{6} & \multirow[t]{2}{*}{$\operatorname{Exp}$} & $(4,4)$ & $(4,4)$ & $(4,4)$ & $(4,4)$ & $(4,4)$ & $(4,4)$ \\
\hline & & & 7.2328 & 7.2286 & 7.2356 & 7.3624 & 7.3604 & 7.3638 \\
\hline & & \multirow[t]{2}{*}{ Erl } & $(4,4)$ & $(4,4)$ & $(4,4)$ & $(4,4)$ & $(4,4)$ & $(4,4)$ \\
\hline & & & 7.2080 & 7.2037 & 7.2111 & 7.3450 & 7.3429 & 7.3464 \\
\hline & & \multirow[t]{2}{*}{ HExp } & $(4,4)$ & $(4,4)$ & $(4,4)$ & $(4,4)$ & $(4,4)$ & $(4,4)$ \\
\hline & & & 7.3579 & 7.3598 & 7.3567 & 7.4518 & 7.4527 & 7.4512 \\
\hline & & \multirow[t]{2}{*}{ MNC } & $(4,4)$ & $(4,4)$ & $(4,4)$ & $(4,4)$ & $(4,4)$ & $(4,4)$ \\
\hline & & & 7.2787 & 7.2748 & 7.2814 & 7.3947 & 7.3929 & 7.3960 \\
\hline & & \multirow[t]{2}{*}{ MPC } & $(4,4)$ & $(4,4)$ & $(4,4)$ & $(4,4)$ & $(4,4)$ & $(4,4)$ \\
\hline & & & 7.3282 & 7.3245 & 7.3307 & 7.4296 & 7.4279 & 7.4309 \\
\hline & \multirow{10}{*}{8} & \multirow[t]{2}{*}{ Exp } & $(3,4)$ & $(3,4)$ & $(3,4)$ & $(3,4)$ & $(3,4)$ & $(3,4)$ \\
\hline & & & 9.4935 & 9.4902 & 9.4957 & 9.7144 & 9.7129 & 9.7155 \\
\hline & & \multirow[t]{2}{*}{ Erl } & $(3,4)$ & $(3,4)$ & $(3,4)$ & $(3,4)$ & $(3,4)$ & $(3,4)$ \\
\hline & & & 9.4694 & 9.4660 & 9.4717 & 9.6977 & 9.6961 & 9.6988 \\
\hline & & \multirow[t]{2}{*}{ HExp } & $(3,4)$ & $(3,4)$ & $(3,4)$ & $(3,4)$ & $(3,4)$ & $(3,4)$ \\
\hline & & & 9.6194 & 9.6211 & 9.6183 & 9.8030 & 9.8038 & 9.8025 \\
\hline & & \multirow[t]{2}{*}{ MNC } & $(3,4)$ & $(3,4)$ & $(3,4)$ & $(3,4)$ & $(3,4)$ & $(3,4)$ \\
\hline & & & 9.5381 & 9.5351 & 9.5402 & 9.7455 & 9.7441 & 9.7465 \\
\hline & & \multirow[t]{2}{*}{ MPC } & $(3,4)$ & $(3,4)$ & $(3,4)$ & $(3,4)$ & $(3,4)$ & $(3,4)$ \\
\hline & & & 9.5876 & 9.5847 & 9.5895 & 9.7799 & 9.7786 & 9.7809 \\
\hline
\end{tabular}

Table 2: Total expected cost rate as a function of $\left(s_{1}, s_{2}\right)$

Example 3: Next, consider the impact of $c_{f_{1}}$ and $c_{f_{2}}$ on the total expected cost rate. For this, consider the following values for the parameters and costs:

$D_{0}=H_{0}, D_{1}=0.3 H_{1}, D_{2}=0.4 H_{1}, D_{12}=0.3 H_{1}, \lambda=8, \beta=0.5, \gamma_{1}=0.6, \gamma_{2}=0.5, p_{i}=0.55^{*} 0.45^{i-1}$, $i=1,2, \ldots, c_{h_{1}}=0.01, c_{h_{2}}=0.01, c_{s}=10, c_{s h_{1}}=0.8, c_{s h_{2}}=1.5, c_{s h_{12}}=1$.

The graphs of the total expected cost rate as a function of $c_{f_{1}}$ and $c_{f_{2}}$ for the three lead time processes and the five demand processes are shown in Figures 2 to 6 . In all the figures the lead time distributions Exp, Erl, and HExp are coloured blue, black, and red respectively. Note the following:

- In all five arrival processes, as $C_{f_{1}}$ and $C_{f_{2}}$ increase simultaneously, the total expected cost rate increases. But the increasing rate for $c_{f_{2}}$ is high compared with $c_{f_{1}}$.

- The Erlang lead time process is associated with a low total expected cost rate, and for the hyper exponential lead time process case the total expected cost rate is high. 


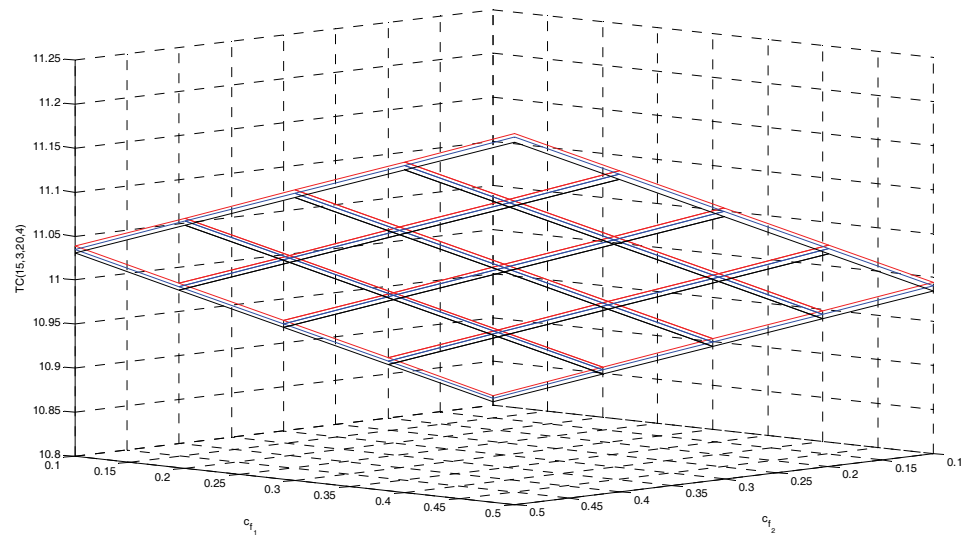

Figure 2: Exp demand process

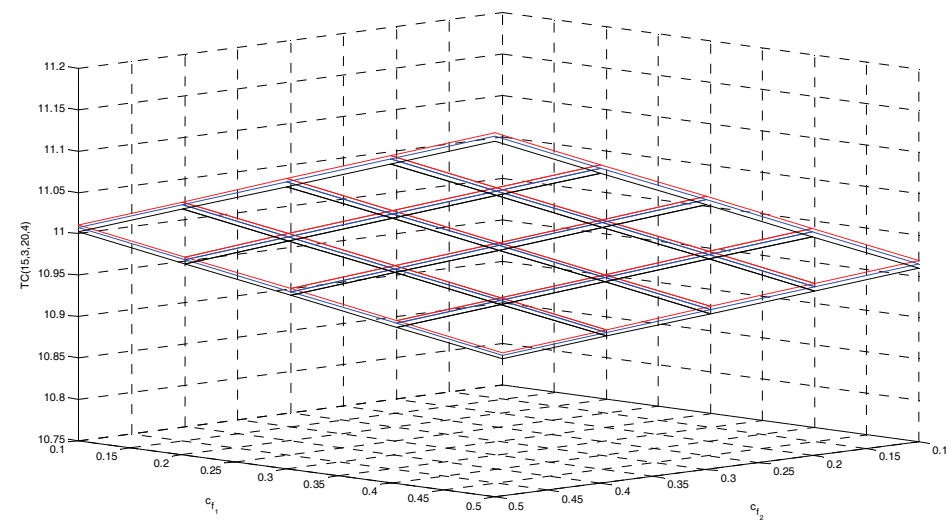

Figure 3: Erl demand process

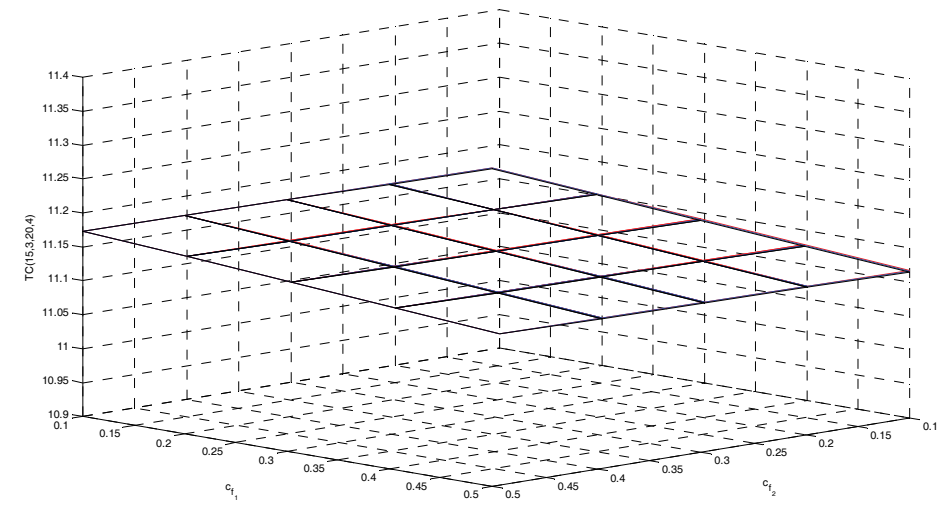

Figure 4: HExp demand process 


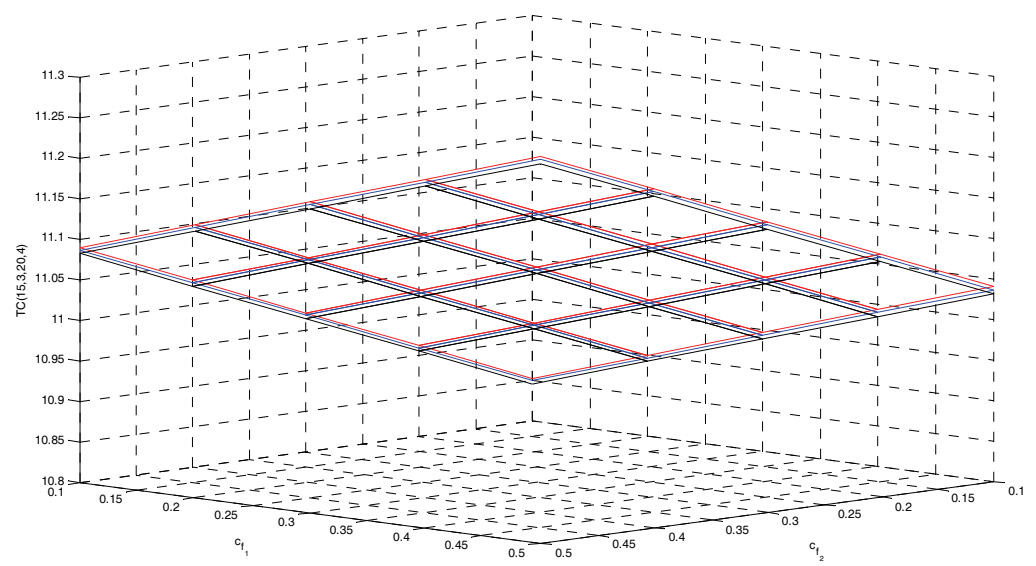

Figure 5: MNC demand process

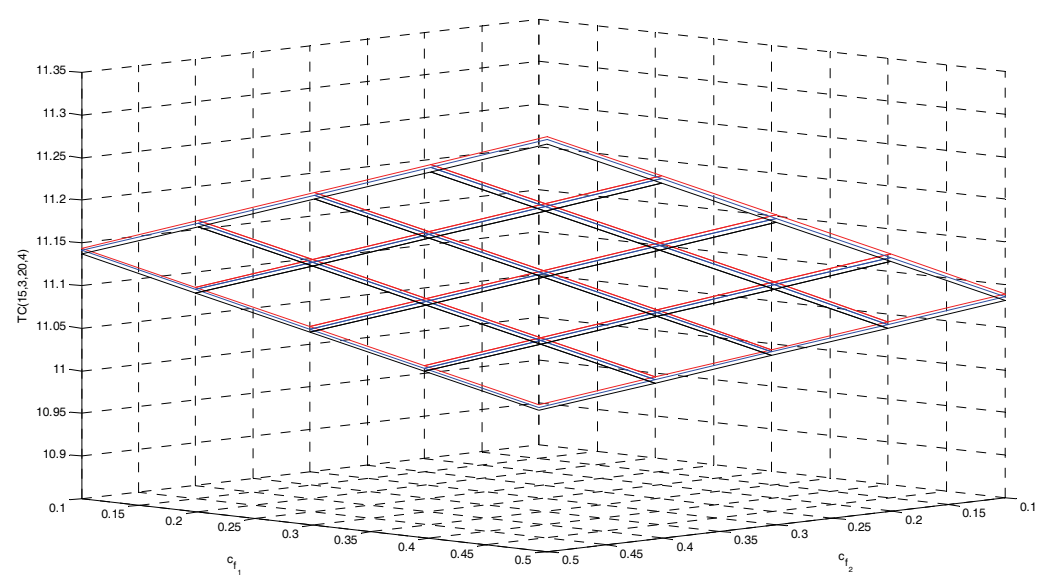

Figure 6: MPC demand process

Example 4: In the final example, the impact of $c_{h_{1}}$ and $c_{h_{2}}$ on the total expected cost rate is shown. Consider the following values for the parameters and costs:

$$
\begin{aligned}
& D_{0}=H_{0}, D_{1}=0.3 H 1, D_{2}=0.4 H 1, D_{12}=0.3 H 1, \lambda=15, \beta=2, \gamma_{1}=0.8, \gamma_{2}=0.4, p_{i}=0.6 * 0.4^{i-1}, \\
& i=1,2, \ldots, c_{s}=10, c_{s h_{1}}=0.8, c_{s h_{2}}=1.5, c_{s h_{12}}=1, c_{f_{1}}=0.2, c_{f_{2}}=0.2 .
\end{aligned}
$$

The graphs of the total expected cost rate as a function of $c_{f_{1}}$ and $c_{f_{2}}$ for the three lead time processes and the five demand processes are shown in Figures 7 to 11. In all the figures the plots for the lead time distributions Exp, Erl, and HExp are coloured blue, black, and red respectively. The following may be observed:

- In all five arrival processes, as $c_{h_{1}}$ and $c_{h_{2}}$ increase, the total expected cost rate increases. But the increasing rate for $c_{h_{2}}$ is high compared with that of $c_{h_{1}}$.

- For all the demand processes, the Erlang lead time process has a low total expected cost rate, and a hyper exponential lead time process has a high total expected cost rate.

- The difference between the total expected cost rates for any two lead time processes is high, except for the HExp demand process. For the HExp demand process, the difference between the total expected cost rates for any two lead time processes is low. 


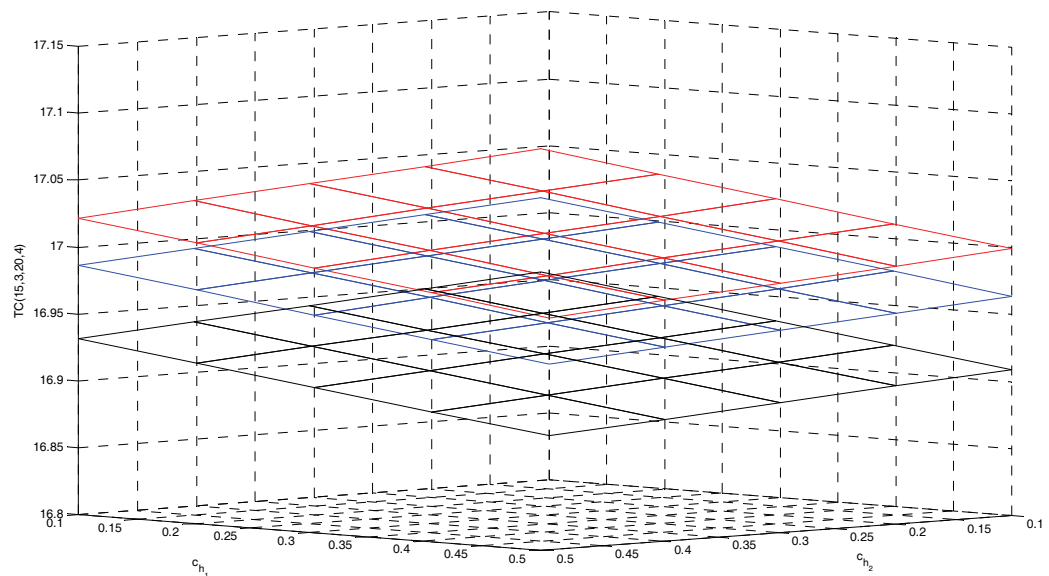

Figure 7: Exp demand process

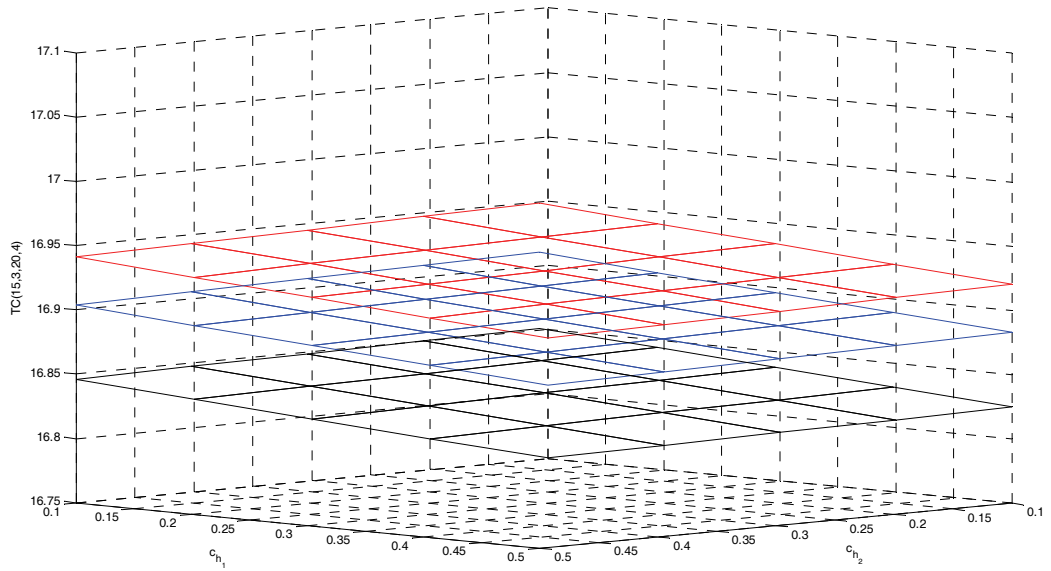

Figure 8: Erl demand process

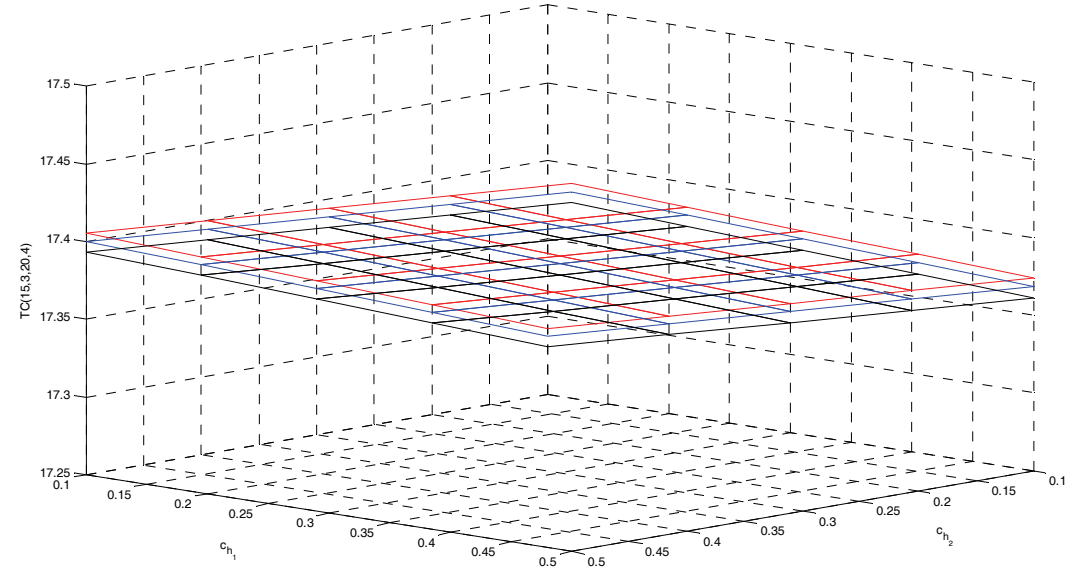

Figure 9: HExp demand process 


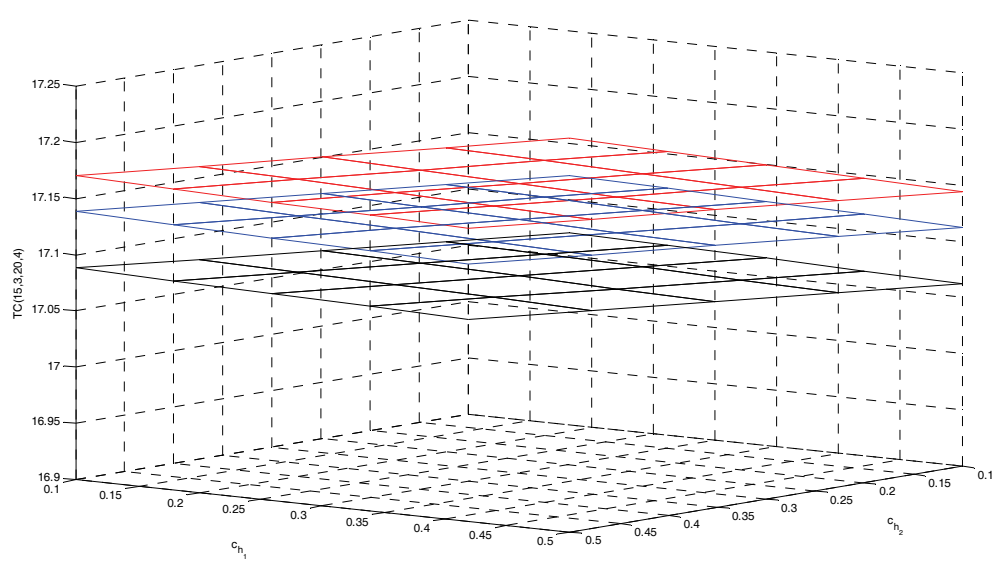

Figure 10: MNC demand process

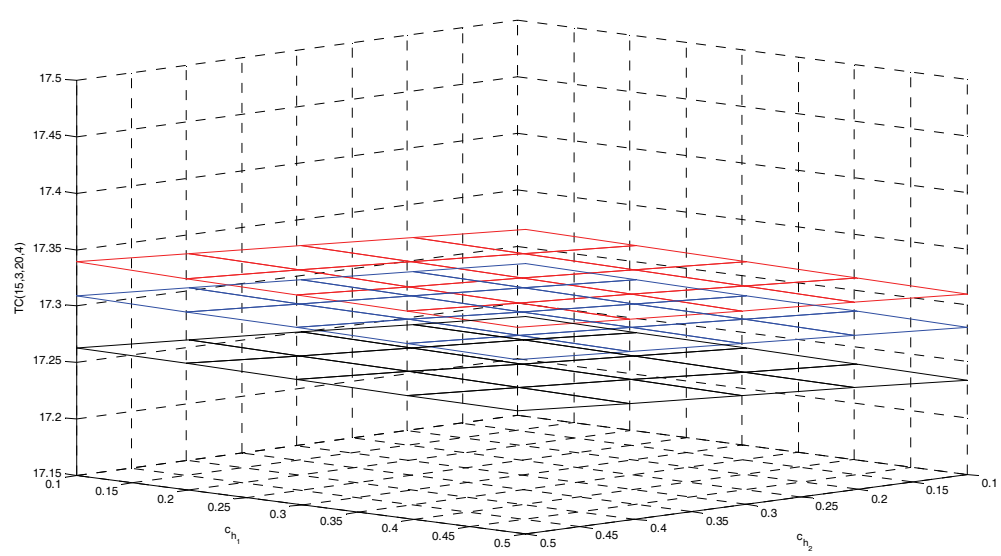

\section{CONCLUSION}

Figure 11: MPC demand process

This research has extended the existing work on two-commodity continuous review inventory systems by introducing perishability for both commodities, Markov arrival processes for demand time points, and a phase type distribution for lead time. It is also assumed that one of the commodities may accept bulk demands. Steady state solutions are also provided for the joint distribution of inventory levels. For a suitable cost structure, the total expected cost rate in the steady state has been determined. To demonstrate the computability of results derived here, ample numerical illustrations are given. Numerical analysis of the effect of the parameters and costs on the total expected cost rate is given.

\section{ACKNOWLEDGEMENTS}

V.S.S. Yadavalli would like to thank the National Research Foundation (NRF) for their financial support. G. Arivarignan would like to thank the CSIR - India, for their financial support (No. 25 (156)/07/EMR-II).

\section{REFERENCES}

[1] Anbazhagan, N. \& Arivarignan, G. 2000, Two-commodity continuous review inventory system with coordinated reorder policy, International Journal of Information and Management Sciences, 11(3), pp. 19-30. 
[2] Anbazhagan, N. \& Arivarignan, G. 2001, A two-commodity coordinated inventory system with renewal demands, Electronnoe modelirovanie, 23(2), pp. 5-16 (in Russian).

[3] Anbazhagan, N. \& Arivarignan, G. 2001, Analysis of two-commodity Markovian inventory system with lead time, The Korean Journal of Computational and Applied Mathematics, 8(2), pp. 427-438.

[4] Anbazhagan, N. \& Arivarignan, G. 2003, Two-commodity inventory system with individual and joint ordering policies, International Journal of Management and Systems, 19(2), pp. 129-144.

[5] Agarwal, V. 1984, Coordinated order cycles under joint replenishment multi-item inventories, Naval Logistic Research Quarterly, 31(1), pp. 131-136.

[6] Balintfy, J.L. 1964, On a basic class of inventory problems, Management Science, 10 (2), pp. 287-297.

[7] Chakravarthy, S. 2001, The batch Markovian arrival process: A review and future work, Advances in Probability and Stochastic Processes, A. Krishnamoorthy et al., (eds), Notable Publication Inc., New Jersey, USA, pp. 21-49.

[8] Chakravarthy, S. \& Dudin, A. 2003, Analysis of a retrial queueing model with MAP arrivals and two types of customers, Mathematical and Computer Modelling, 37(3-4), pp. 343-363.

[9] Federgruen, A., Groenvelt, H. \& Tijms, H.C. 1984, Coordinated replenishment in a multi-item inventory system with compound Poisson demands, Management Science, 30(3), pp. 344-357.

[10] Fung, R.Y.K. \& Ma, X. 2001, A new method for joint replenishment problems, Journal of the Operational Research Society, 52(3), pp. 358-362.

[11] Goyal, S.K. 1973, Determination of economic packaging frequency of items jointly replenished, Management Science, 20(2), pp. 232-235.

[12] Goyal, S.K. 1974, Determination of optimal packaging frequency of jointly replenished items, Management Science, 21(4), pp. 436-443.

[13] Goyal, S.K. 1988, Economic ordering policy for jointly replenished items, International Journal of Production Research, 26(7), pp. 1237-1240.

[14] Goyal, S.K. \& Satir, T. 1989, Joint replenishment inventory control: Deterministic and stochastic models, European Journal of Operations Research, 38(1), pp. 2-13.

[15] Kalpakam, S. \& Arivarignan, G. 1993, A coordinated multi-commodity $(s, S)$ inventory system, Mathematical and Computer Modelling, 18(11), pp. 69-73.

[16] Kaspi, M. \& Rosenblatt, M.J. 1991, On the economic ordering quantity for jointly replenished items, International Journal of Production Research, 29(1), pp. 107-114.

[17] Latouche, G. \& Ramaswami, V. 1999, Introduction to matrix analytic methods in stochastic modelling, SIAM, Philadelphia.

[18] Lee, G. \& Jeon, J. 2000, A new approach to an N/G/1 queue, Queueing Systems, 35, pp. 317-322.

[19] Li, Q.L. \& Li, J.J. 1994, An application of Markov-modulated Poisson process to two-unit series repairable system, Chinese Journal of Engineering Mathematics, 11(1), pp. 56-66.

[20] Lucantoni, D.M. 1991, New results on the single server queue with a batch Markovian arrival process, Stochastic Models, 7(1), pp. 1-46.

[21] Lucantoni, D.M. 1993, The BMAP/G/1 queue : A tutorial, in Models and techniques for performance evaluation of computer and communications systems, L. Donatiello and R. Nelson (eds), Springer-Verlag, New York, pp. 330-358.

[22] Lucantoni, D.M., Meier-Hellstern, K.S., \& Neuts, M.F. 1990, A single server queue with server vacations and a class of non-renewal arrival processes, Advances in Applied Probability, 22, pp. 676-705.

[23] Miller, B.L. 1971, A multi-item inventory model with joint probability back-order criterion, Operations Research, 19(6), pp. 1467-1476.

[24] Neuts, M.F. 1994, Matrix-geometric solutions in stochastic models: An algorithmic approach, Dover Publications Inc. New York.

[25] Neuts, M.F. 1989, Structured stochastic matrices of M/G/1 type and their applications, Marcel Dekker.

[26] Neuts, M.F. 1995, Matrix-analytic methods on the theory of queues, in Advances in 
queueing: Theory, methods and open problems, J.H. Dshalalow (ed.), CRC, pp. 265-292.

[27] Nilsson, A., Segerstedt, A. \& van der Sluis, E. 2007, A new iterative heuristic to solve the joint replenishment problem using a spreadsheet technique, International Journal of Production Economics, 108(1-2), pp. 399-405.

[28] Nilsson, A. \& Silver, E.A. 2008, A simple improvement on Silver's heuristic for the joint replenishment problem, Journal of the Operational Research Society, 59(10), pp. 1415-1421.

[29] Olsen, A.L. 2005, An evolutionary algorithm to solve the joint replenishment problem using direct grouping, Computers and Industrial Engineering, 48(2), pp. 223-235.

[30] Ramaswami, V. 1981, The N/G/1 queue and its detailed analysis, Advances in Applied Probability, 12, pp. 222-261.

[31] Silver, E.A. 1974, A control system for coordinated inventory replenishment, International Journal of Production Research, 12(6), pp. 647-671.

[32] Silver, E.A. 1976, A simple method of determining order quantities in joint replenishments under deterministic demand, Management Science, 22(12), pp. 1351-1361.

[33] Sivakumar, B., Anbazhagan, N., \& Arivarignan, G. 2005, A two-commodity perishable inventory system, ORiON, 21(2), pp. 157-172.

[34] Sivakumar, B., Anbazhagan, N., \& Arivarignan, G. 2006, Two-commodity continuous review perishable inventory system, International Journal of Information and Management Sciences, 17(3), pp. 47-64.

[35] Srinivasan, S.K. \& Ravichandran, N. 1994, Multi-item $(S, s)$ inventory model with Poisson Demand, general lead time and adjustable re-order size, in G.V. Krishna Reddy et al. (Reviewed edited), Proceedings of the Conference of Stochastic Models, Optimization and Computer Application, Wiley Eastern Limited, pp. 226-236.

[36] Thomstone, T.M. \& Silver, E.A. 1975, A coordinated inventory control system, International journal of Production Research, 13(6), pp. 581-602.

[37] Van Eijs, M.J.G. 1993, A note on the joint replenishment problem under constant demand, Journal of the Operational Research Society, 44(2), pp. 185-191.

[38] Viswanathan, S. 1996, A new optimal algorithm for the joint replenishment problem, Journal of the Operational Research Society, 47(7), pp. 936-944.

[39] Viswanathan, S. 2002, On optimal algorithms for the joint replenishment problem, Journal of the Operational Research Society, 53(11), pp. 1286-1290.

[40] Viswanathan, S. 2007, An algorithm for determining the best lower bound for the stochastic joint replenishment problem, Operations Research, 55(5), pp. 992-996.

[41] Wildeman, R.E., Frenk, J.B.G. \& Dekker, R. 1997, An efficient optimal solution method for the joint replenished problem, European Journal of Operational Research, 99(2), pp. 433-444.

[42] Yadavalli, V.S.S., Anbazhagan, N. \& Arivarignan, G. 2004, A two-commodity continuous review inventory system with lost sales, Stochastic Analysis and Applications, 22(2), pp. 479-497. 
http://sajie.journals.ac.za 